\title{
O CONHECIMENTO DE PUÉRPERAS SOBRE A TRIAGEM NEONATAL*
}

\author{
Ediálida Costa Santos ${ }^{1}$, Maria Aparecida Munhoz Gaíva², Janaina Gomes dos Santos ${ }^{3}$, Simone Mourão Abud ${ }^{4}$
}

\begin{abstract}
RESUMO: A triagem neonatal, popularmente conhecida como "teste do pezinho", permite rastrear indivíduos com probabilidade de apresentar determinadas patologias, realizando o diagnóstico em estágio precoce e instituindo tratamento específico, de modo a evitar sequelas graves e aumentar a sobrevida dos acometidos. Trata-se de um estudo descritivo, de abordagem quantitativa, realizado com 55 puérperas multíparas, cujos dados foram coletados por meio de questionário semiestruturado e teve como objetivo analisar o conhecimento das puérperas em relação à importância da triagem neonatal. Os resultados apontam baixa compreensão das puérperas a respeito da importância da triagem, apesar de a maioria ter conhecimento da realização do exame nos filhos; elas desconheciam a idade ideal para realizar a triagem e receberam informação de enfermeiros sobre o teste no momento da alta hospitalar. Diante o exposto, faz-se necessário incluir o tema nas consultas pré-natal e repensar sobre os métodos de orientações empregados às mães.
\end{abstract}

PALAVRAS-CHAVE: Triagem neonatal; Recém-nascido; Educação em saúde; Enfermagem.

\section{WHAT MOTHERS KNOW ABOUT NEONATAL TRIAGE}

ABSTRACT: Neonatal triage, commonly known as the 'heel prick test', permits the tracing of individuals with probability of presenting certain determined pathologies, and the making of a diagnosis at an early stage and instituting specific treatments, in order to avoid serious consequences and increase the survival time of the ill. This was a descriptive study, with a quantitative approach, carried out with 55 new mothers with prior births, whose data were collected via semistructured questionnaires and had as objective to analyse the mothers' knowledge in relation to neonatal triage. The results indicate that they have little knowledge in respect to neonatal triage, although the majority were familiar with the exam being carried out on their children; they did not know the ideal age for the triage to be made, and received information from the nurses about the test at the moment of discharge from hospital. This being so, it becomes necessary to include the subject in the pre-natal consultancies and to re-think the advisory methods used with the mothers.

KEYWORDS: Neonatal triage; New-born; Health education; Nursing.

\section{EL CONOCIMIENTO DE PUÉRPERAS ACERCA DE LA TRIADA NEONATAL}

RESUMEN: Es "test del piecito" permite disgnosticar individuos con probabilidad de presentar determinadas patologías, realizando el diagnóstico en estagio precoz y instituyendo tratamiento específico, de modo a evitar secuelas graves y aumentar la sobrevida de los pacientes. Se trata de un estudio descriptivo, de abordaje cuantitativo, realizado con 55 puérperas multíparas, cuyos datos fueron recogidos por medio de cuestionario semiestructurado y tuvo como objetivo analizar el conocimiento de las puérperas acerca de la importancia de la triada neonatal. Los resultados apuntan baja comprensión de las puérperas sobre la importancia de la triada, a pesar de la mayoría conocer el examen de los hijos; ellas desconocían la edad ideal para realizar la triada y fueron informadas por los enfermeros sobre el test en el momento de la alta hospitalar. Delante del expuesto, se hace necesario añadir el tema en las consultas prenatales y repensar los métodos de orientación a las madres.

PALABRAS CLAVE: Triada neonatal; Recién nacido; Educación en salud; Enfermería.

\footnotetext{
*Parte do Trabalho de Conclusão do Bacharelado em Enfermagem 2010/01 da Universidade do Estado de Mato Grosso. ${ }^{1}$ Enfermeira. Mestranda em Saúde Coletiva na Universidade Federal de Mato Grosso - UFMT.

${ }^{2}$ Enfermeira. Doutora em Enfermagem em Saúde Pública. Professora da UFMT. Líder do Grupo Pesquisa Projeto Argos. Pesquisadora do CNPq.

${ }^{3}$ Enfermeira do Pronto Atendimento Médico em Cáceres - MT. Professora da Universidade do Estado de Mato Grosso.

${ }^{4}$ Enfermeira. Mestranda em Enfermagem na UFMT. Professora do Curso de Enfermagem do Centro Universitário de Várzea Grande - MT.
}

\author{
Autor correspondente: \\ Ediálida Costa Santos \\ Universidade do Estado de Mato Grosso \\ R. Manuel Ramos Lino, Q-39 - 786201-000- Cuiabá-MT-Brasil \\ E-mail: maydadis@hotmail.com
}

Recebido: 02/02/11

Aprovado: 03/05/11

Cogitare Enferm. 2011 Abr/Jun; 16(2):282-8 


\section{INTRODUÇÃO}

A triagem neonatal permite rastrear indivíduos com probabilidade de apresentar determinadas patologias metabólicas, hematológicas, infecciosas e genéticas, e, com isso, realizar o diagnóstico em estágio precoce, na fase assintomática do período neonatal, instituindo o tratamento específico para minimizar ou eliminar as sequelas decorrentes ${ }^{(1)}$.

A Organização Mundial de Saúde (OMS), na década de 1960, preconizava a adoção de programas para a triagem neonatal (TN) nos países em desenvolvimento. No Brasil, a iniciativa pioneira de implementação veio da Associação dos Pais e Amigos dos Excepcionais de São Paulo, que desde 1976 realiza a TN para fenilcetonúria ${ }^{(2)}$. No ano de 1990, a Lei 8069 - Estatuto da Criança e do Adolescente - determinou que os estabelecimentos de atenção à gestante deveriam oferecer exames visando o diagnóstico e terapêutica de anormalidades no metabolismo do recém-nascido, bem como prestar orientações aos pais ${ }^{(3)}$.

Com o objetivo de ampliar a cobertura às doenças metabólicas, unificar a assistência e torná-la integral ao usuário, em 2001 o Ministério da Saúde criou o Programa Nacional de Triagem Neonatal (PNTN) classificando-o em três fases, de acordo com os tipos de doenças triadas, visando à detecção precoce, busca ativa dos indivíduos suspeitos, confirmação diagnóstica, acompanhamento e tratamento, além da criação de um banco de dados nacional ${ }^{(2)}$.

Popularmente conhecido como "teste do pezinho" (TP), a triagem é realizada através da coleta de sangue com papel-filtro na região calcânea do recém-nascido, área bastante vascularizada. O momento para a coleta, de preferência, não deve ser inferior a 48 horas de alimentação protéica (amamentação) e nunca superior a 30 dias, sendo o ideal entre o $3^{\circ}$ e o $7^{\circ}$ dia de vida ${ }^{(2)}$. A detecção precoce, ainda no período neonatal, permite intervir no curso natural da doença, promovendo em possíveis casos o tratamento ou evitando sequelas mais graves $^{(1)}$.

O PNTN foi instituído para a prevenção de doenças incuráveis, porém, que apresentam um bom prognóstico se diagnosticadas e tratadas desde o período neonatal. Sua relevância e efetividade têm sido apontadas pela OMS para a redução da incidência da deficiência mental, principalmente em países em desenvolvimento ${ }^{(2)}$.

A coleta do teste, se realizada após o trigésimo dia de vida, coloca em risco a efetividade da $\mathrm{TN}$ e, por isso, torna-se crucial que a informação sobre a importância da triagem seja oferecida aos familiares desde o prénatal. A maneira como esta informação é repassada durante o pré-natal e após o nascimento é um fator que pode aumentar a probabilidade de pais/familiares terem uma compreensão adequada da importância da $\mathrm{TN}$ e, assim, levarem seus filhos para a realização do TP no tempo adequado.

Por outro lado, a desinformação, tanto dos profissionais quanto dos pais, pode influenciar negativamente na realização do teste, comprometendo o diagnóstico precoce e o início do tratamento. Pesquisa realizada junto ao programa de triagem neonatal na Cidade de Belém, Estado do Pará identificou que a maioria dos pais/familiares que procuraram o serviço para realizar o TP desconhecia o seu objetivo e as patologias que podem ser identificadas, bem como a possibilidade de prevenção de sequelas quando o diagnóstico é feito precocemente $^{(4)}$.

O conhecimento sobre os danos causados pelas doenças e a necessidade de tratamento precoce podem influenciar positivamente na realização do exame em período adequado e no interesse em buscar o resultado. Partindo da premissa que toda criança nascida em território nacional tem o direito à $\mathrm{TN}$, compreendemos que a orientação com relação ao TP desde o pré-natal até o pós-parto é de suma importância para que as gestantes/ puérperas e familiares entendam a necessidade do teste. Este estudo tem como objetivo analisar o conhecimento das puérperas com relação à importância da $\mathrm{TN}$.

\section{METODOLOGIA}

Trata-se de um estudo descritivo de abordagem quantitativa realizado durante o mês de março de 2010 no alojamento conjunto de uma maternidade do $\mathrm{Mu}-$ nicípio de Cáceres - Mato Grosso. Essa maternidade é filantrópica e referência do Sistema Único de Saúde para as gestações de baixo risco nesse município.

Os critérios adotados para a inclusão das puérperas no estudo foram: idade superior a 18 anos; ser multípara; ter no mínimo um filho nascido vivo, ou seja, já ter passado por período puerperal e cujos partos tenham ocorrido a partir do ano de 2001 (ano de implementação do PNTN no Mato Grosso); ter realizado o pré-natal no Município de Cáceres ou, em algum momento da gestação atual ou anterior, ter usufruído dos serviços relacionados à atenção à gestante ou trabalho de parto nesse município. Assim, a amostra totalizou 55 puérperas.

Os dados foram coletados por meio de entrevista, 
utilizando instrumento semiestruturado elaborado para atender os objetivos do estudo e com perguntas direcionadas aos aspectos de identificação da puérpera, do Serviço de Saúde e da TN.

Todas as informações coletadas foram codificadas e armazenadas em um banco de dados no formato Excel, que possibilitou a organização das informações e posterior análise. As respostas das questões fechadas foram agrupadas segundo as variáveis estudadas, sendo que o número de consultas pré-natais e escolaridade materna foram apresentadas de acordo com a Declaração de Nascido Vivos (DNV). Os formulários foram enumerados sequencialmente em P1, P2, P3...P55. Utilizou-se a estatística descritiva para apresentação dos resultados, adotando-se distribuições e frequências (absolutas e relativas) e medidas descritivas. As respostas das questões abertas foram transcritas e agrupadas por temas, sendo apresentadas as falas mais relevantes.

$\mathrm{O}$ estudo atendeu aos requisitos da Resolução n. 196/96, do Conselho Nacional de Saúde, sendo aprovado pelo Comitê de Ética em Pesquisa da Universidade de Cuiabá, sob número 205 CEP/UNIC/ 2009 - protocolo n. 2009-207.

\section{RESULTADOS}

Foram entrevistadas 55 puérperas que se adequaram aos critérios de inclusão e compuseram o banco de dados da pesquisa. A média de idade das puérperas foi de 26 anos $(\mathrm{DP}=4,83)$, sendo que a maior parte delas possuía entre 4 a 11 anos de estudo e nenhum caso de analfabetismo (Tabela 1). A maioria das entrevistadas não possuía ocupação externa à residência, sendo que $85,4 \%$ (47) eram donas de casa e 14,5\% (8) possuíam ocupação fora de suas casas, dessas, algumas desempenhavam atividades de doméstica, secretária e ajudante de produção, ou eram estudantes.

No estudo 3,6\% (2) das puérperas afirmaram não ter realizado consulta pré-natal, 49,1\% (27) realizaram de 4 a 6 consultas, $87,3 \%$ (48) realizaram o acompanhamento pré-natal exclusivamente no Sistema Único de Saúde, $7,3 \%$ (4) na rede privada e 1,8\% (1) na rede pública e privada.

Questionadas se conheciam ou já tinham ouvido falar sobre o TP, 10,9\% (6) das entrevistadas responderam desconhecer o teste e $89,9 \%$ (49) afirmaram saber de sua existência. As mães que afirmaram desconhecer o TP possuíam média de 27 anos de idade ( $\mathrm{DP}=2,65)$, a maioria tinha escolaridade entre 4 e 7 anos de estudos concluídos. Quando indagadas sobre a solicitação de
Tabela 1 - Escolaridade em anos de estudos concluídos e número de consultas pré-natal das puérperas entrevistadas. Cáceres, 2010

\begin{tabular}{lcc}
\hline \multicolumn{1}{c}{ Variáveis } & $\mathbf{N}$ & $\mathbf{\%}$ \\
\hline Escolaridade & & \\
1-3 anos & 03 & 5,4 \\
$4-7$ anos & 23 & 41,8 \\
8-11 anos & 25 & 45,5 \\
$\geq 12$ anos & 04 & 7,3 \\
\hline Total & $\mathbf{5 5}$ & $\mathbf{1 0 0}$ \\
\hline Consultas pré-natal & & \\
\hline Nenhuma consulta & 2 & 3,6 \\
1-3 consultas & 11 & 20 \\
4-6 consultas & 27 & 49,1 \\
$\geq 7$ consultas & 15 & 27,3 \\
\hline Total & $\mathbf{5 5}$ & $\mathbf{1 0 0}$ \\
\hline
\end{tabular}

algum exame para o bebê após o nascimento, a maioria, timidamente, relatou que não foi orientada ou solicitada a realizar exames no bebê após o nascimento. A maioria referiu conhecimento sobre o TP:

Eu entendo assim: não tem aquela marquinha que coloca no papel? Não é aquilo lá? (P49)

Chegou a falar na segunda [gravidez], né? Mas fiquei com dó e não levei. [Questionada se ela sabia como seria esse exame] Era, né, de furar o pezinho? (P31)

Observa-se que a puérpera identificada como P49, se confunde em relacionar o TP ao procedimento de impressão plantar do recém-nascido para a DNV e cartão da criança. Já no relato da P31, percebe-se que a mesma recebeu orientação com relação ao TP, porém, não levou o seu filho por considerar o teste um procedimento doloroso.

Entre as entrevistadas, 89\% (49) afirmaram conhecer o TP. As respostas dessas mulheres foram agrupadas em temas apresentados na tabela 2 .

No que concerne aos conhecimentos que as puérperas possuíam sobre o $\mathrm{TP}$, um expressivo número o associou à descoberta de doenças no recém-nascido, porém não citou quais seriam essas doenças ou possíveis agravos delas decorrentes:

O Teste do Pezinho tira sangue pra ver se a criança tem algum problema, ou doença. O que eu sei é isso, mas que tipo de doença eu não sei. (P9)

Eu sei que é bom e interessante para saber se tem algum 
Tabela 2 - Conhecimento das puérperas a respeito do Teste do Pezinho. Cáceres, 2010

\begin{tabular}{lccc}
\hline Conhecimento sobre o teste & Realizaram o teste & Não realizaram & Total \\
& & & 7 \\
Não soube explicar/conhecimento insuficiente & 7 & 0 & 8 \\
Conhecimento equivocado & 8 & 0 & 5 \\
Reconheceu sua necessidade, mas não informou a finalidade & 5 & 1 & 18 \\
Associou ao diagnóstico de doenças & 17 & 1 & 1 \\
Associou à coleta de sangue & 0 & 4 & 7 \\
Associou à coleta de sangue e diagnóstico de doenças & 3 & 0 & 3 \\
Associou ao diagnóstico de doenças e tratamento & 3 & $\mathbf{6}$ & $\mathbf{4 9}$ \\
\hline Total & $\mathbf{4 3}$ & \\
\hline
\end{tabular}

tipo de problema. [Questionada sobre a importância] Acho, pelo que dizem, através dele sabe se o neném nasce com algum problema de cabeça, algo assim. (P44)

Houve mulheres que verbalizaram não saber explicar sobre o teste ou sentiram que o conhecimento que possuíam era insuficiente $(14,3 \%$; 7). Da mesma forma, houve quem respondeu que realizou o teste por ouvir falar que é necessário, mas não soube explicar o porquê de sua realização $(10,2 \% ; 5)$, como explicitado:

Mais ou menos, ah não sei muita coisa. Prá te falar a verdade, acho que não sei nada. (P22)

Olha, eu já fiz ele. Eles sempre falam, mas eu nem sei. [Questionada sobre a importância] É importante, por eles falarem que é importante a gente acha que é. (P30)

Eu fiz, só. Mas não sei ao certo o significado. (P16)

Entre as mães que conheciam o teste e não o realizaram nos filhos anteriores $(10,9 \% ; 6)$, a maioria possuía em comum a baixa escolaridade (4 a 7 anos de estudo) e desconheciam com quantos dias é indicada a realização do exame. Elas relataram:

Eu quero até falar, que da minha menina eu não fiz porque fizeram a cabeça do meu marido falando que furava o pé da criança tudinho. Aí, meu marido não quis que furasse. (P21)

Já ouvi falar que é bom para identificar se ele tem algum problema. [Questionada sobre a importância]. Bom eu acho, mas eu nunca fiz; eu acho assim, que judia com aquela agulha. (P10)

Observa-se, pelos relatos dessas mães, a associação do TP ao procedimento de coleta de sangue, fato este que pode ser um dos motivos que pese na decisão de não-realização do mesmo.

Um pequeno grupo de mulheres $(6,1 \% ; 3)$ associou o teste à descoberta de doenças e à realização de tratamento, porém, o sentido do tratamento foi apenas curativo. Essas puérperas não referiram a importância da descoberta precoce e o caráter preventivo de sequelas, nem a melhora da qualidade de vida da criança.

Segundo os relatos, as orientações sobre o teste foram dadas na alta hospitalar da gestação anterior, sendo que durante o pré-natal poucas receberam informações sobre o teste. Quando indagadas sobre a pessoa que informou, independente de ter sido no pré-natal ou alta hospitalar, $51 \%$ (25) relataram que receberam a informação do enfermeiro, 22,4\% (11) das mulheres afirmaram ser o médico quem as orientou, para $6,1 \%$ (3) a informação foi dada por amigos ou familiares e $20,4 \%$ (10) não recordavam de quem receberam as informações.

Ao ser indagadas sobre a idade recomendada para realização do TP, $42,8 \%$ (21) das puérperas não souberam informar (Tabela 3).

Entre as 43 puérperas que haviam realizado o teste

Tabela 3 - Distribuição das puérperas segundo as respostas sobre a idade recomendada para a realização do Teste do Pezinho. Cáceres, 2010

\begin{tabular}{lll}
\hline $\begin{array}{l}\text { Idade recomendada } \\
\text { para o exame }\end{array}$ & $\mathbf{N}$ & $\mathbf{\%}$ \\
\hline Até 7 dias & 14 & 28,6 \\
Até 30 dias & 14 & 28,6 \\
Não sabem & 21 & 42,8 \\
\hline Total & $\mathbf{4 9}$ & $\mathbf{1 0 0}$ \\
\hline
\end{tabular}


anteriormente, ao serem indagadas sobre o retorno para buscar o resultado do exame no prazo estabelecido pela unidade de coleta, observou-se que $18,6 \%$ (8) não retornaram e que $81,3 \%$ (35) retornaram. Entre as mulheres que retornaram para buscar o resultado, $60,5 \%$ (21) afirmaram não haver problema algum com o resultado, e não fizeram referência a alguma doença triada. Por outro lado, 39,5\% (14) disseram não recordar do resultado.

\section{DISCUSSÃO}

Ainda que o PNTN tenha sido implantado no Estado de Mato Grosso há quase dez anos, percebe-se dificuldade em sua divulgação entre as participantes.A falta de conhecimento de pais/cuidadores sobre a TN tem sido evidenciada em outros estudos em diferentes regiões do país ${ }^{(4-6)}$.

Neste estudo, o desconhecimento das mães decorre da falta de informação e também da dificuldade em assimilar a orientação recebida, visto que houve confusão ao relacioná-lo à marca da impressão plantar e a não associação ao nome do exame. Tais fatores também poderiam estar relacionados a baixa escolaridade do grupo estudado.

A forma como a informação é repassada pelo profissional de saúde, por exemplo, é um fator que pode aumentar a probabilidade dos pais terem uma compreensão adequada sobre o que é o TP e a importância de fazê-lo em idade adequada. Assim, a desinformação pode influenciar na realização, ou não, do teste, o que pode ser observado nos maus-entendimentos relatados por pais, como o medo de machucar o bebê ou acreditar que já tenha sido feito o teste no filho, confundido com a impressão plantar rotineiramente realizada na maternidade. Por conseguinte, não se dirigem ao posto de coleta após a alta da maternidade ${ }^{(4)}$.

As mães que disseram conhecer o TP, porém não o realizaram nos seus filhos, ainda que o associem a descoberta de doenças inespecíficas, também o relaciona ao procedimento doloroso, fato esse que pode ser o motivador da sua decisão. Em virtude do desconhecimento da real importância do exame, a triagem fica em segundo plano por conta da dor momentânea causada pelo procedimento. Isso pode ser minimizado com orientações quanto à importância das doenças triadas, da necessidade de realização precoce e da prevenção de agravos. Além disso, explicar como será realizado o exame diminui a ansiedade dos pais. Nesse sentido, também podem ser tomadas medidas de conforto - como manter a criança no colo materno - pois o bebê se sentirá protegido pelo abraço da mãe e ela própria se sentirá mais "competente" em proteger o filho. Essas ações, além de educativas, proporcionam segurança e tranquilidade às mães/familiares quanto a eventuais receios que possam existir em relação à coleta ${ }^{(6)}$.

As mães que afirmaram conhecer o TP, e que o realizaram nos filhos anteriores, demonstraram possuir um conhecimento superficial sobre o teste, sua finalidade e quais patologias são identificadas por ele. Tais resultados são semelhantes aos encontrados em outra pesquisa sobre a temática ${ }^{(4)}$.

Como já evidenciado ${ }^{(4)}$, a maioria dos pais é orientada somente sobre a necessidade de realizar o TP, mas não recebe informações sobre o aspecto preventivo da $\mathrm{TN}$, das consequências das patologias e dos procedimentos que compõem as etapas da triagem.

As orientações a respeito da $\mathrm{TN}$, na maioria da vezes, têm sido repassadas na alta hospitalar da maternidade, mesmo que o PNTN defina as responsabilidades das instituições de saúde e assegure que todos estabelecimentos que prestam assistência à gestante são responsáveis por oferecer orientações aos pais ${ }^{(2)}$. Considerando que a maioria das puérperas realizou o número mínimo de seis consultas pré-natais, definidas pelo Ministério da Saúde, faz-se necessário rever como são realizadas as ações de educação em saúde durante o pré-natal nas Unidades Básicas de Saúde, já que o momento em que a mãe recebe as orientações pode influenciar no seu aprendizado. Deve-se evitar o momento da alta para orientar a mãe sobre os cuidados com seu filho, já que o processo de educação para a saúde deve ser realizado também durante todo o prénatal e na internação para o parto ${ }^{(7)}$.

Observando os resultados, destaca-se o papel do enfermeiro na divulgação de informações sobre o TP, tendo em vista que este foi o profissional que mais informou as mães sobre a TN. Podemos associar este resultado ao fato de ser o enfermeiro quem mais tem contato com o público-alvo (mães) durante o processo de atenção ao pré-natal, parto e puerpério. As orientações, por meio da educação em saúde, fazem parte das atribuições do enfermeiro, independente do espaço de atuação, e é um importante e necessário instrumento de cuidado ${ }^{(8)}$. Entretanto, faz-se necessário que todos os profissionais que atuam junto às gestantes e puérperas se sintam responsáveis por disseminar as informações sobre o TP.

A pesquisa mostrou que um grande número de mulheres desconhecia a idade recomendada para a rea- 
lização do exame. Um estudo que avaliou o serviço de referência em TN do Estado de Mato Grosso mostrou que em $63 \%$ dos testes realizados no ano de $2003 \mathrm{e} \mathrm{em}$ $66,2 \%$ dos realizados em 2004, a coleta da amostra de sangue foi feita entre o $8^{\circ}$ e o $30^{\circ}$ dia após o nascimento. Verificou-se percentual considerável de crianças, tanto em 2003 como em 2004, que teve amostras coletadas em idade superior a 30 dias de vida, ou seja, 9,8\% e $9 \%$, respectivamente ${ }^{(9)}$.

$\mathrm{O}$ desconhecimento de grande parte das puérperas sobre a idade correta para a realização da triagem pode revelar a deficiência na assimilação da informação recebida, ou até mesmo a falta de preparo dos profissionais sobre a $\mathrm{TN}$, visto que a maioria das mães relatou ter recebido a informação apenas de profissional de saúde. Assim, faz-se necessário para a área da saúde - em especial na enfermagem, que majoritariamente atua nesses serviços - o acesso a ações de educação permanente, sensibilização e conhecimentos técnico-científicos sobre a TN, visando a efetividade das ações de prevenção e a melhoria da assistência prestada ${ }^{(6)}$.

O desconhecimento sobre a importância da TN também se revela, ao considerar o número de mães que não retornaram para buscar o resultado do exame e aquelas que não recordavam o laudo. Entre as mães que não retornaram, pode-se supor que alguns fatores estão envolvidos, tais como: desinteresse dos pais pelo resultado; dificuldade de acesso à unidade de coleta (única no município), por residir em bairros distantes; e a não-realização de busca ativa dos pacientes com resultados alterados por parte do município. Estudo realizado na Cidade de Belém, Pará, que avaliou a compreensão de 200 pais/cuidadores sobre a TN, evidenciou que $28 \%$ não tinham ido buscar o resultado do teste após um mês da realização da coleta ${ }^{(4)}$.

É importante que os pais retornem para buscar os laudos do exame, pois ainda que o PNTN determine a busca ativa dos pacientes com resultados alterados caso aconteça dificuldades ou falhas na comunicação com a família - se esta retornar à Unidade no prazo estipulado diminui o risco de ampliar o tempo de atraso para a reconvocação ${ }^{(2)}$. Os resultados devem ser repassados às famílias e anexados à Caderneta de Saúde da Criança, e a equipe da Unidade de Saúde deve informar, claramente, o resultado à família, bem como os laudos também devem indicar o resultado de maneira clara ${ }^{(2)}$.

O papel dos profissionais de saúde no TP é extremamente importante, desde a informação inicial às mães sobre a necessidade de realizá-lo, até a busca pelo resultado, pois, eles são agentes multiplicadores de informações e orientações na prevenção dos agravos diagnosticados pela $\mathrm{TN}$ e de suas sequelas.

\section{CONCLUSÃO}

Os resultados da pesquisa apontam um baixo nível de compreensão das puérperas a respeito da TN. Foi grande o número de mães que associou a triagem a um exame para descoberta de doenças ou anormalidades quaisquer. A noção de que o TP pode detectar doenças crônicas e graves e prevenir sequelas, se diagnosticado precocemente, não foi claramente evidenciado. Mesmo apresentando conhecimento insuficiente a respeito do teste, de modo geral, as mulheres levam seus filhos para a realização do exame por indicação do profissional de saúde e também por acreditarem que teriam benefícios para a saúde do filho.

As informações sobre o TP foram oferecidas às puérperas, em sua maioria, na alta hospitalar. Entretanto, deve-se considerar a importância de incluir o tema nas orientações durante as consultas de pré-natal. Isso deve melhorar a compreensão da informação, em virtude do tempo maior que o profissional de saúde tem para responder às dúvidas a respeito da $\mathrm{TN}$, no decorrer da gestação.

Observamos também quão grande é a importância da Enfermagem no processo de educação em saúde na TN. Assim, faz-se necessário repensar os métodos de orientação empregados para gestantes e puérperas. Cabe também priorizar ações de educação permanente nos serviços de saúde que enfoquem a TN, para ampliar o conhecimento dos profissionais e assim melhorar a qualidade da assistência.

O PNTN é composto por várias etapas, que culmina na proposta de tratamento precoce e prevenção de sequelas. A conscientização da importância do programa e da necessidade de realizar cada etapa em tempo hábil é o primeiro passo para um atendimento eficaz.

\section{REFERÊNCIAS}

1. Leão LL, Aguiar MJB. Triagem neonatal: o que os pediatras deveriam saber. J Pediatr. [Internet] 2008; 84(4) [acesso em 07 jun 2010]. Disponível: http:// www.scielo.br/scielo.php?script $=$ sci_arttext\&pid $=$ S0021-75572008000500012

2. Ministério da Saúde (BR). Manual de normas técnicas e rotinas operacionais do programa nacional de triagem 
neonatal. $2^{\mathrm{a}}$ ed. amp. Brasília: Ministério da Saúde; 2004.

3. Brasil. Lei n. 8.069, de 13 de Julho de 1990. Dispõe sobre o Estatuto da Criança e do Adolescente e dá outras providências. Diário Oficial da União [Internet] 16 jul. 1990. [acesso em 19 abr 2011] Disponível: http://www. planalto.gov.br/ccivil_03/leis/18069.htm

4. Garcia MG, Ferreira EAP, Oliveira FPS. Análise da compreensão de pais acerca do teste do pezinho. Rev Bras Crescimento Desenvolv Hum. 2007;17(1):1-12.

5. Oliveira FPS, Ferreira EAP. Adesão ao tratamento do hipotireoidismo congênito segundo relato de cuidadores. Psicol Reflex Crit. 2010;23(1):19-28.

6. Silva MBGM, Zagonel IS, Lacerda MR. Enfermagem na triagem neonatal. Acta Sci Health Sci. [Internet] 2003;25(2) [acesso em 12 dez 2010]. Disponível: http:// periodicos.uem.br/ojs/index.php/ActaSciHealthSci/ article/view/2226/1454

7. Amorim JF, Souza MHN. O conhecimento das mães acerca da triagem neonatal. Rev Enferm UERJ. [Internet] 2005;13(1) [acesso em 08 Jun 2010]. Disponível: http://www.facenf.uerj.br/v13n1/v13n1a04. pdf

8. Taube SAM, Silva MCEP. A educação em saúde para portadores de doença crônica oftálmica: um relato de experiência. Cogitare Enferm. 2004;9(2):66-72.

9. Stranieri I, Takano OA. Avaliação do serviço de referência em triagem neonatal para hipotireoidismo congênito e fenilcetonúria no estado de Mato Grosso, Brasil. Arq Bras Endocrinol Metabol. [Internet] 2009;53(4) [acesso em 06 Jun 2010]. Disponível: http://migre.me/51LDf 